\title{
Effect of reproductive management programs for first service on replacement dairy heifer economics
}

\author{
M. Masello, ${ }^{1} \odot$ M. M. Perez, ${ }^{1} \oplus$ G. E. Granados, ${ }^{1} \odot$ M. L. Stangaferro, ${ }^{1} \oplus$ B. Ceglowski, ${ }^{2}$ M. J. Thomas, ${ }^{2} \odot$ \\ and J. O. Giordano ${ }^{1 *}$ (1) \\ ${ }^{1}$ Department of Animal Science, Cornell University, Ithaca, NY 14853 \\ ${ }^{2}$ Dairy Health and Management Services, Lowville, NY 13367
}

\begin{abstract}
Our objective was to evaluate cash flow for dairy heifers managed for first service with programs that relied primarily on insemination at detected estrus (AIE), timed AI (TAI), or a combination of both. Holstein heifers from 2 commercial farms were randomized to receive first service with sexed semen after the beginning of the AI period (AIP) at 12 mo of age with 1 of 3 treatments: (1) PGF+AIE (n = 317): AIE after $\mathrm{PGF}_{2 \alpha}$ injections every $14 \mathrm{~d}$ (up to 3) starting at the beginning of the AIP; heifers not AIE $9 \mathrm{~d}$ after the third PGF $_{2 \alpha}$ were enrolled in the 5d-Cosynch (5dCP) protocol; (2) ALLTAI $(\mathrm{n}=315)$ : TAI after ovulation synchronization with the 5dCP protocol; and (3) PGF+TAI ( $=334)$ : AIE after $2 \mathrm{PGF}_{2 \alpha}$ injections $14 \mathrm{~d}$ apart (second $\mathrm{PGF}_{2 \alpha}$ at beginning of AIP). If not AIE $9 \mathrm{~d}$ after the second $\mathrm{PGF}_{2 \alpha}$, the $5 \mathrm{dCP}$ protocol was used for TAI. After first service heifers were AIE or received TAI after the $5 \mathrm{dCP}$ with conventional semen. Individual heifer cash flow (CF) for up to a 15 -mo period (d $0=$ beginning of AIP) was calculated using reproductive cost (rearing only), feed cost (rearing only), income over feed cost (lactation only), calf value, operating cost, and with or without replacement cost. A stochastic analysis with Monte Carlo simulation was used to estimate differences in $\mathrm{CF}$ for a range of market values for inputs and outputs. Time to pregnancy for up to $100 \mathrm{~d}$ after the beginning of the AIP was analyzed by Cox's proportional regression, binary data with logistic regression, and continuous outcomes by ANOVA. Time to pregnancy (hazard ratio and $95 \% \mathrm{CI}$ ) was reduced for the ALL-TAI versus the PGF+AIE treatment $(1.20 ; 1.02-1.42)$, but it was similar for ALL-TAI and PGF+TAI (1.13; 0.95-1.33) and the PGF+AIE and PGF+TAI treatments (1.07; 0.91-1.25). The proportion of heifers not pregnant by $100 \mathrm{~d}$ did not differ $(\mathrm{PGF}+\mathrm{AIE}=7.0 \%$; $\mathrm{PGF}+\mathrm{TAI}=$
\end{abstract}

Received March 24, 2020.

Accepted September 1, 2020.

*Corresponding author: jog25@cornell.edu
$6.5 \%$; ALL-TAI $=6.8 \%)$. When including replacement cost, $\mathrm{CF}$ (\$/slot per $15 \mathrm{mo}$ ) differences were $\$ 51$ and $\$ 42$ in favor of the PGF+TAI and ALL-TAI compared with the PGF+AIE treatment, and $\$ 9$ in favor of the PGF+TAI compared with the ALL-TAI treatment but did not differ statistically. Excluding heifers that were replaced to evaluate the effect of timing of pregnancy differences only, the difference in CF between the PGF+AIE with the PGF+TAI and ALL-TAI treatment was the same (i.e., \$15) and favored the programs that used more TAI, but also did not differ statistically. Stochastic simulation results were in line with those of the deterministic analysis confirming the benefit of the programs that used more TAI. We concluded that submission of heifers for first service with TAI only or TAI in combination with AIE generated numerical differences in CF of potential value to commercial dairy farms. Reduced rearing cost and increased revenue during lactation increased CF under fixed (not statistically significant) or simulated variable market conditions.

Key words: cash flow, pregnancy, synchronization, dairy heifer

\section{INTRODUCTION}

Raising replacement heifers is a critical task for dairy operations as it provides the future revenue-generating units of a herd. Nevertheless, the heifer rearing period (RP) is financially nonproductive and therefore a large investment for most dairy farms. Estimations of heifer rearing cost indicated that the heifer enterprise might represent as much as 15 to $20 \%$ of total operating expenses (Harsh et al., 2001; Karszes, 2014), with no financial return until heifers enter the milking herd. Therefore, management strategies designed to reduce the cost of the heifer-raising program may have a pronounced effect on the overall profitability of dairy farms. Of particular interest are approaches aimed at optimizing age at first calving (AFC) to reduce days on feed and thus, raising cost (Ettema and Santos, 2004). In addition, earlier incorporation of heifers to 
the milking herd shortens the time required for a dairy cow to attain positive lifetime cash flow (Ettema and Santos, 2004).

As management strategies aimed at reducing the time required for heifers to reach breeding size are limited and gestation length is fixed, one of the few management opportunities to optimize AFC is reducing time to pregnancy after the beginning of the artificial insemination period (AIP). This might be accomplished by implementing proactive reproductive management programs that maximize the insemination and conception risk after heifers reached the appropriate size to become pregnant. In this regard, Masello et al. (2019) reported that a first service program designed to increase the insemination risk by using timed AI (TAI) after synchronization of ovulation with a 5d-Cosynch protocol for all heifers at the beginning of the AIP (i.e., ALL-TAI program) reduced time to pregnancy when compared with a program that relied on insemination after induction of estrus with up to $3 \mathrm{PGF}_{2 \alpha}$ treatments every $14 \mathrm{~d}$. In addition, a program that combined AI at detected estrus (AIE) for $9 \mathrm{~d}$ after $2 \mathrm{PGF}_{2 \alpha}$ treatments $14 \mathrm{~d}$ apart and TAI for heifers not AIE resulted in similar time to pregnancy relative to the ALL-TAI program. Although results from this experiment suggested that programs that reduce days to first service with ALL-TAI or a combination of AIE and TAI might benefit heifer reproductive performance, ultimately the choice of program for most commercial farms should be based on economic outcomes for the heifer enterprise. In particular, because there are multiple potential interactions among factors that affect cash flow of reproductive management programs. For example, programs for first service that rely more on synchronization of estrus and TAI might be more expensive to implement due to the increased labor and cost for hormonal treatments but may improve cash flow of the heifer enterprise by reducing raising cost and earlier generation of revenue during lactation.

Thus, the primary objective of this study was to compare cash flow and parameters of economic performance for heifers enrolled in the experiment reported in Masello et al. (2019). Specifically, our objective was to analyze individual heifer cash flow for a fixed period of time (i.e., $15 \mathrm{mo}$ ) after the beginning of the AIP. A secondary objective was estimating variation in cash flow through stochastic Monte Carlo simulation to estimate differences between treatments under different pricing scenarios observed under the varying market conditions in which dairy farms operate. We hypothesized that systematic use of reproductive management programs that hastened insemination through more aggressive use of TAI would be more expensive to implement but would increase accumulated cash flow relative to a pro- gram that relied primarily on AIE after $\mathrm{PGF}_{2 \alpha}$-induced estrus.

\section{MATERIALS AND METHODS}

All procedures performed with heifers were approved by the Animal Care and Use Committee of Cornell University.

\section{Farms and Heifer Management}

Information about farms, animals, and experimental procedures are described in detail in Masello et al. (2019). Briefly, nulliparous Holstein heifers from 2 commercial dairy farms located in New York State were enrolled in this experiment (Farm A located in Washington county and Farm B located in Wayne county), from November 2015 to February 2017. In both farms, heifers were housed in freestall barns with concrete flooring and self-locking headgates in the feeding lane. Freestall surfaces were covered with mattresses and either sand (Farm A) or dried manure bedding (Farm B). Heifers were fed a total mixed ration once a day with unlimited access to feed and water. The diet was formulated to meet or exceed the requirements for a Holstein heifer weighing $450 \mathrm{~kg}$ and gaining $0.8 \mathrm{~kg} / \mathrm{d}$ (Cornell Net Carbohydrate and Protein System, Higgs et al., 2015).

\section{Experimental Treatments}

Once a month, heifers $(n=966)$ of $>310 \mathrm{~d}$ of age were stratified by age in days and then randomly allocated to 1 of 3 treatments by the dairy herd management software (DairyComp305, ValleyAg Software, Tulare, CA). Treatments consisted of different reproductive management strategies for first AI service with sexed semen. Heifers became eligible for insemination (i.e., beginning of the AIP) at $368 \pm 10 \mathrm{~d}$ of age.

In Farm A, estrus detection for all AI services was performed once a day by a combination of visual observation of behavioral signs of estrus and tail-paint removal, whereas only visual observation was used in Farm B. In Farm A, heifers were inseminated immediately after detection of estrus, whereas in Farm B heifers were inseminated 6 to $12 \mathrm{~h}$ after observation of behavioral estrus (performed inseminations twice a day).

Heifers in the treatment with PGF and AIE $(\mathbf{P G F}+\mathbf{A I E} ; \mathrm{n}=317)$ received AIE after synchronization of estrus with up to $3 \mathrm{PGF}_{2 \alpha}$ treatments every 14 d starting on the first day of the AIP. Heifers not AIE for up to $9 \mathrm{~d}$ after the third $\mathrm{PGF}_{2 \alpha}$ treatment received a 5d-Cosynch protocol for synchronization of ovulation 
and timed artificial insemination (TAI). Thus, TAI for heifers not AIE occurred $45 \mathrm{~d}$ after the beginning of the AIP. The 5d-Cosynch protocol consisted of an initial GnRH treatment i.m. plus insertion of a controlled internal drug release insert (CIDR); 5 d later, $25 \mathrm{mg}$ of $\mathrm{PGF}_{2 \alpha}$ s.c. and CIDR removal; and finally, a GnRH treatment and insemination $3 \mathrm{~d}$ after $\mathrm{PGF}_{2 \alpha}$ and CIDR removal. The use of TAI in the PGF+AIE group was a last resort to ensure insemination of all heifers within a reasonable amount of time after the beginning of the AIP rather than a preferred method of submission for AI in this group. For the PGF+TAI $(\mathrm{n}=334)$ treatment, estrus was synchronized with $2 \mathrm{PGF}_{2 \alpha}$ treatments $14 \mathrm{~d}$ apart with the second treatment given at the beginning of the AIP. Heifers not AIE within $9 \mathrm{~d}$ of the second $\mathrm{PGF}_{2 \alpha}$ treatment were enrolled in the $5 \mathrm{~d}$-Cosynch protocol to receive TAI. Thus, all heifers received first service within $17 \mathrm{~d}$ of the beginning of the AIP. Heifers in the ALL-TAI $(\mathrm{n}=315)$ treatment were submitted to the 5d-Cosynch protocol for synchronization of ovulation and TAI. The beginning of the AIP for this treatment group coincided with the time of $\mathrm{PGF}_{2 \alpha}$ treatment and CIDR removal. All heifers in this treatment group received first service within $3 \mathrm{~d}$ of the beginning of the AIP. Heifers from the 3 treatment groups detected in estrus after CIDR removal and the $\mathrm{PGF}_{2 \alpha}$ treatment of $5 \mathrm{~d}$-Cosynch until the day before TAI received AIE with no GnRH treatment.

Heifers in the 3 treatment groups failing to conceive to first or subsequent inseminations received AI with conventional semen after detection of estrus or TAI. Re-inseminations at detected estrus occurred any time after a previous insemination. Heifers diagnosed nonpregnant through transrectal ultrasonography $31 \pm 3$ $\mathrm{d}$ after a previous insemination were enrolled $2 \mathrm{~d}$ after nonpregnancy diagnosis in the $5 \mathrm{~d}$-Cosynch protocol for resynchronization of ovulation and TAI. In both farms, pregnancy diagnosis was conducted by transrectal ultrasonography (Easi-Scan, BCF Technology Ltd., Livingston, UK) of the reproductive tract and ovaries AI by a veterinarian in Farm $\mathrm{A}$ and a technician from the research team in Farm B. Heifers re-inseminated before pregnancy diagnosis were considered not pregnant to the previous AI.

Seventeen heifers were removed from the experiment because after experiencing pregnancy loss were moved to a pen where natural service occurred, but individual services were not recorded.

\section{Calculation of Economic Outcomes}

For heifers that calved within 15-mo after the beginning of the AIP, 2 different periods of time were evaluated for economic outcomes: (1) the RP, defined as the time from the beginning of the AIP until first calving or herd exit due to death or sale, and (2) the first lactation period (FLP), defined as the time from first calving until completion of a total of 15 mo after the initiation of the AIP for individual heifers. Conversely, for heifers that did not calve within 15 mo of the beginning of the AIP, the economic outcomes were only evaluated for the RP. To estimate cash flow per slot (i.e., unit of space at the dairy occupied by each heifer at the beginning of the AIP), all expenses during the RP (reproductive cost, feed cost, replacement cost, and other operating expenses) and expenses (feed cost, replacement cost, and other operating expenses) and revenues (milk sales and calf value) during the FLP were estimated for each heifer enrolled for 15 mo after initiation of the AIP. The choice of 15 mo to evaluate cash flow was to provide most heifers enough time to complete the RP and generate data for their first lactation before pregnancy could have a substantial effect on milk production (i.e., assuming some cows could become pregnant at $50 \mathrm{DIM})$. A total of 15 mo provided heifers that became pregnant on the first day of the AIP a maximum of 174 DIM in their first lactation, assuming a gestation length of $\sim 280 \mathrm{~d}$ and $30.4 \mathrm{~d} / \mathrm{mo}$. In addition, to better represent the herd replacement dynamics under conditions of constant herd size and a stable in- and out-flow of lactating cows, we assumed that slots initially occupied by a heifer in the experiment would be occupied at all times during the 15-mo period. Thus, if a heifer left the herd during the RP or the FLP, a virgin heifer (i.e., replacement period initiated at the beginning of the AIP) or a recently calved first lactation cow (i.e., replacement period initiated at first calving) replaced the heifer or cow that left, respectively. In both cases, replacements were randomly selected from the pool of heifers and cows enrolled in the experiment so that a heifer or lactating cow from the same farm and treatment was used to replace the one that left the herd. Therefore, each slot for the heifer or cow that left the herd was occupied until the end of the 15-mo period by heifers or cows that could better represent the conditions of each farm and treatment. All expenses (reproductive, feed, and other operating expenses) and income (milk sales, calf value) generated by the replacement where accounted for the calculation of cash flow per slot. A particular slot may have been occupied by more than 2 different heifers or cows if the replacement heifer or cow also left the herd during the 15-mo study period.

Although the analysis of interest was cash flow including the effect of the replacement dynamics, a second analysis was conducted to estimate cash flow without the effect of the replacement dynamics. This was done to isolate the effect of timing of pregnancy 
because replacement cost could have profound effects on overall cash flow.

Thus, cash flow was estimated for each heifer or each slot for 15 mo by subtracting the total RP cost from the total FLP profit. Total RP cost and FLP profit were calculated using the following equations:

$$
\begin{gathered}
\text { Total RP cost }=\text { Repro }+ \text { FC }+ \text { Replac }+ \text { OE } \\
\text { Total FLP profit }=\text { IOFC }+ \text { Calf Value } \\
- \text { Replac }- \text { OE },
\end{gathered}
$$

where Repro $=$ cost of implementing reproductive management program, $\mathrm{FC}=$ feed cost, $\mathrm{Replac}=\mathrm{re}-$ placement cost, $\mathrm{OE}=$ operating expenses, and IOFC = income over feed cost. Price selection for the different inputs included in the deterministic economic analyses represent the economic conditions and market values for the New York State dairy industry during the experimental period (i.e., November 2015 to June 2018).

Reproductive Cost. Cost incurred during the RP was calculated for each slot and was the aggregation of the costs associated with all AI services (i.e., hormonal treatment for synchronization of estrus and ovulation, semen for AI, and labor for hormonal treatments), pregnancy testing, and detection of estrus during the 15-mo period. Reproductive cost generated during the FLP, if any, were not included in the analysis. For hormonal treatments, cost of a dose of $\mathrm{GnRH}, \mathrm{PGF}_{2 \alpha}$, and each CIDR device were set at $\$ 1.72, \$ 2.21$, and $\$ 11.92$, respectively. Reproductive hormones costs were obtained from the local veterinary clinic that provided products to these farms during the experiment. Labor cost for application of hormonal treatment and insertion of intravaginal progesterone releasing devices was set at $\$ 15 / \mathrm{h}$. Thus, assuming that an operator can give 60 injections per hour, average labor cost for injections was set at $\$ 0.25$ per injection, whereas the cost of applying an intravaginal progesterone releasing device was set at $\$ 0.75$ per device assuming application of 20 CIDR devices per hour. The cost of a unit of sexed-sorted $(\$ 25)$ and of conventional $(\$ 12)$ semen was estimated based on the blend price of semen units of different genetic merit and for the volume of sales representative of the size of the farms in the current experiment. Labor cost associated with each insemination was set at $\$ 1$, assuming 15 inseminations per hour. Pregnancy testing was set at $\$ 2.75$ per examination based on a cost of $\$ 110 / \mathrm{h}$ and 40 heifers examined per hour based on data provided by a bovine practitioner involved with the research. Estrus detection cost was calculated based on a total of $1.25 \mathrm{~h}$ of detection per day at $\$ 15 / \mathrm{h}$ of labor divided by the average daily number of heifers to be observed, which resulted on an average of $\$ 0.028$ / heifer per day of rearing.

Body Weight Estimation. During the RP, BW was modeled daily for every heifer using the Gompertz growth function as previously described in Winsor (1932):

$$
\mathrm{BW}(\mathrm{kg})=\mathrm{A} \times \exp \{-\exp [\mathrm{B}-(\mathrm{C} \times \text { age })]\},
$$

where age $=$ heifer age in days, $\mathrm{A}=$ asymptotic weight or maximum growth response, $\mathrm{B}=$ scale parameter related to initial weight, and $\mathrm{C}=$ growth rate. Body weight data at different time points during the RP for a subgroup of heifers $(\mathrm{n}=572)$, BW of mature (i.e., third and fourth lactation) cows $(\mathrm{n}=30)$, and BW at first calving were only available for Farm B $(\mathrm{n}=489)$. To generate the curve, all body weight data were combined $(\mathrm{n}=1,308)$ and plotted against age in days. The Gompertz growth function was then fitted using the Calculate option of the CurveExpert software (version 2.6.5; Hyams, 2011). Parameters A, B, and C for the resulting equation were $695,0.90$, and 0.004 , respectively.

During lactation, BW was modeled daily for every cow using the Korver function as previously described in (van Arendonk, 1985):

$$
\begin{gathered}
\mathrm{BW}(\mathrm{kg})=\mathrm{A} \times\left\{1-\left[1-(\mathrm{B} / \mathrm{A})^{1 / 3}\right]\right. \\
\times \exp (-\mathrm{C} \times \text { age })\}^{3}-(\mathrm{P} 1 / \mathrm{P} 2) \\
\times \mathrm{DIM} \times \exp (1-\mathrm{DIM} / \mathrm{P} 2)
\end{gathered}
$$

where age $=$ cow age in days, $\mathrm{A}=$ mature live weight $(\mathrm{kg}), \mathrm{B}=$ birth weight $(\mathrm{kg}), \mathrm{C}=$ growth rate, $\mathrm{P} 1=$ maximum decrease in live weight during lactation, and $\mathrm{P} 2$ = time during lactation with minimum live weight. Data used for average mature live weight $(720 \mathrm{~kg})$ and birth weight $(39 \mathrm{~kg})$ were retrieved from both farms. Parameters C, P1, and P2 were 0.004, 30, and 60, respectively, based on (Kalantari et al., 2010).

Daily Milk and FCM Production Estimation. The MilkBot model (Ehrlich, 2013) was used to estimate daily milk production for each heifer that calved during the study period (i.e., within 15 mo after the beginning of the AIP). Details about MilkBot parameters and daily milk yield calculations have been previously described (Ehrlich, 2013). Briefly, monthly milk data were retrieved from the dairy herd management software to estimate individual lactation curves based on 4 parameters: scale, ramp, offset, and decay. For heifers that calved but left the herd before the second monthly milk test (i.e., either no milk data available or only available for the first test, $\mathrm{n}=45$ ), daily milk production was calculated based on the average of each param- 
eter corresponding to the same farm and experimental treatment as the heifer that left the herd. Inclusion of a few monthly test data points (e.g., 2 or less) results in less reliable estimation of milk yield. Nevertheless, the proportion of cows with only 2 test-days available was small and similar across treatments $(\mathrm{PGF}+\mathrm{AIE}=6 \%$, $\mathrm{PGF}+\mathrm{TAI}=4 \%$, and ALL-TAI $=5 \%$ ). Therefore, we did not expect bias for milk production estimations as a result of an unbalanced proportion of cows with few monthly test data points.

To estimate daily DMI during lactation, FCM was calculated based on daily milk weight $(\mathrm{kg} / \mathrm{d})$ estimated by the MilkBot and monthly test fat percentage as follows:

$$
\begin{gathered}
\mathrm{FCM}(\mathrm{kg} / \mathrm{d})=0.4 \times \mathrm{DMW}+0.15 \\
\times \text { Fat } \% \times \mathrm{DMW}
\end{gathered}
$$

where DMW = daily milk weight $(\mathrm{kg} / \mathrm{d})$ estimated by the MilkBot model, and Fat $\%=$ fat percentage reported in the monthly milk tests. Because daily milk fat percentage data were not available, fat percentage for a specific monthly test was repeated for a 30-d period (i.e., value obtained from first test was used from 1 to 30 DIM, value from second test was used from 31 to 60 DIM, and so on).

Feed Cost. For both the RP and the FLP, feed cost was calculated based on the total DMI for each individual slot multiplied by the cost of each $\mathrm{kg}$ of DM. Feed cost was set at $\$ 0.17$ per $\mathrm{kg}$ of DM from the beginning of the AIP until the beginning of the close-up period (i.e., $\geq 259 \mathrm{~d}$ in gestation) for which feed cost was set at $\$ 0.22 / \mathrm{kg}$ of DM. On the other hand, feed cost was set at $\$ 0.29 / \mathrm{kg}$ during the lactation period.

DMI Estimation. Daily DMI for individual heifers was estimated using NRC (2001) equations. During the $\mathrm{RP}, \mathrm{DMI}$ was estimated as a function of BW, as

$$
\begin{gathered}
\text { DMI }(\mathrm{kg} / \mathrm{d})=\mathrm{BW}^{0.75} \times\left\{\left[\left(0.2435 \times \mathrm{NE}_{\mathrm{m}}\right)\right.\right. \\
\left.\left.-\left(0.0466 \times \mathrm{NE}_{\mathrm{m}}{ }^{2}\right)-\text { SubFact }\right] / \text { DivFact }\right\}
\end{gathered}
$$

where $\mathrm{NE}_{\mathrm{m}}=$ net energy of diet for maintenance (Mcal/ $\mathrm{kg})$, SubFact $=$ adjustment for effects of age above or below 12 mo, and DivFact = dietary concentration adjustment factor above or below $1 \mathrm{NE}_{\mathrm{m}}$. Because the age of all heifers enrolled in the experiment was at least 12 mo, the adjustment for the effect of age (SubFact) was set at 0.0869 . In addition, because the $\mathrm{NE}_{\mathrm{m}}$ of the diets offered to heifers from both farms was greater than 1 (i.e., $1.54 \mathrm{Mcal} / \mathrm{kg}$ ), the adjustment for dietary concentration (DivFact) was set at 1.54 (i.e., equivalent to $\mathrm{NE}_{\mathrm{m}}$ of the diet). Additionally, because intake decreases immediately before calving, an adjustment factor (DMI_factor) for days pregnant was calculated and multiplied by the initial equation as follows (NRC, 2001):

if days pregnant $>210$ and $<259$, then

DMI_factor $=\{1+[(210-$ days pregnant $) \times 0.0025]\}$

if days pregnant $\geq 259$, then

$$
\begin{aligned}
& \text { DMI_factor }=[(1.71-\{0.69 \times \exp [0.35 \\
& \times(\text { days pregnant }-280)]\}) / 100] \times \mathrm{BW} .
\end{aligned}
$$

During lactation, DMI was estimated as a function of FCM, BW, and week of lactation (DIM/7), as

$$
\begin{gathered}
\text { DMI }(\mathrm{kg} / \mathrm{d})=0.372 \times \mathrm{FCM}+0.0968 \times \mathrm{BW}^{0.75} \\
\times\{1-\exp [-0.192 \times(\mathrm{DIM} / 7+3.67)]\} .
\end{gathered}
$$

Calf Value. All heifers that initiated a first lactation during the 15-mo period generated a one-time revenue when the calf was born. Briefly, calving data were retrieved from the dairy herd management software and used to estimate individual calf value based on the number of calves born and the market value based on sex of the calf. The market value for newborn calves was set at $\$ 109$ for female calves, and $\$ 97$ for male calves (Progressive Dairyman, 2019). Calf value was set at $\$ 0$ for heifers with calves born dead (stillbirths).

Replacement Cost. For each heifer that left the herd due to death or sale, the replacement cost was equal to the market value of a replacement heifer minus the salvage value of the heifer sold for beef ( $\$ 0$ if the heifer left the herd due to death), and the value of the calf born from the replacement. The salvage value for heifers or cows sold was calculated based on their estimated BW at the time of sale (i.e., average of 308, 276, and $270 \mathrm{~d}$ after the beginning of the AIP for heifers in the PGF+AIE, PGF+TAI, and ALL-TAI treatments, respectively) times the beef price. During the RP, the value of the calf born from a replacement virgin heifer was $\$ 0$ if the replacement did not calve before the 15 mo period for the slot was completed. In contrast, if the replacement heifer was able to conceive and calve during the replacement period, then the value of the calf born was set at the average calf value obtained in the current experiment ( $\$ 95 /$ calf), which accounts for male, female, stillborn and twin calves. During the FLP, in contrast, calf value was set to $\$ 95$ in all cases based on the assumption that all replacements entering the herd in their first lactation contributed with a 
newborn calf. For replacement cost calculations during the RP, the market value of a virgin heifer was set at $\$ 700$, based on the average value of lean and heavy replacement heifers during the study period (Progressive Dairyman, 2019). In addition, the beef price for heifers sold during the RP was set at $\$ 2.70 / \mathrm{kg}$ (USDA National Agricultural Statistics Service, 2019). In contrast, for replacement cost during the FLP, the market value of a springer heifer (i.e., heifer close to calving) was set at $\$ 1,565$ (USDA Economic Research Service, 2019), and the value of beef for cows sold was set at $\$ 1.50$ (USDA National Agricultural Statistics Service, 2019). Assumed market values were used for purchase cost of heifers to replace those leaving during the RP and cows leaving during lactation because no data were available to estimate raising cost up from birth until the beginning of the AIP for this study.

Milk Income Over Feed Cost. Daily milk income over feed cost (IOFC) was estimated for all heifers that started first lactation during the 15 -mo period by subtracting feed cost from milk revenue (i.e., milk volume $\mathrm{kg} \times$ milk price per $\mathrm{kg}$ ). A slot's IOFC was set to $\$ 0$ when heifers and their corresponding replacement (if present) did not calve within the 15-mo period. Milk price was the average monthly price reported by the Dairy Market Watch report (Cornell Cooperative Extension of Chautauqua County, 2018) from September 2016 (first heifer initiated FLP) to June 2018 (last heifer completed 15-mo experimental period). The weighted average accounting for milk class (class I to IV) usage was $\$ 0.36 / \mathrm{kg}$ (i.e., $\$ 16.5$ per $100 \mathrm{lbs}$ ).

Other Operating Expenses. Other operating expenses not accounted for by reproductive cost, feeding cost, and replacement cost were set at $\$ 0.85 / \mathrm{d}$ per heifer for the RP (Karszes, 2014) and $\$ 3.10 / \mathrm{d}$ per cow during the FLP (Karszes et al., 2017, 2018). During the RP, the calculation of other operating expenses included the following items: hired labor, bedding, veterinary services, machinery operation and ownership, and building and operation ownership. During the FLP, other operating expenses included hired labor, professional nutritional services, machine repairs, rent and lease, fuel, bedding, milking supplies, utilities, and other professional fees. Other operating expenses were calculated for each heifer or cow based on the individual daily expense (rearing $=\$ 0.85$; first lactation $=$ $\$ 3.10$ ) multiplied by the number of days in the RP or in FLP during the 15-mo after the initiation of the AIP.

\section{Stochastic Analysis}

Differences between treatments in cash flow for the 15-mo period (ALL-TAI vs. PGF+AIE, ALL-TAI vs. $\mathrm{PGF}+\mathrm{TAI}$, and $\mathrm{PGF}+\mathrm{TAI}$ vs. $\mathrm{PGF}+\mathrm{AIE})$ under vary- ing input values were estimated by stochastic Monte Carlo simulation models using @Risk software (version 7.5, Palisade Corp., Ithaca, NY). Simulations were run and recorded for 10,000 iterations with replacement. To build the models, reproduction and production outcomes as well as herd exit dynamics observed for the experiment were used as fixed inputs (Supplemental Table S1, https://doi.org/10.3168/jds.2020-18588). Thus, variation for every iteration of the simulation was introduced for hormone cost $\left(\mathrm{GnRH}, \mathrm{PGF}_{2 \alpha}\right.$, and CIDR devices), semen price (sexed and conventional semen), milk price, feed cost, beef price (for culled heifers and cows), price of a replacement heifer or cow, price of a newborn calf (female and male), and fixed cost. Historical data were available from 2010 to 2019 for milk price (USDA Agricultural Marketing Service, 2019), beef price of sold heifers and cows (USDA National Agricultural Statistics Service, 2019), price for replacement heifers (Progressive Dairyman, 2019) and cows (USDA Economic Research Service, 2019), newborn calves (Progressive Dairyman, 2019), and feed cost of lactation period (Gould, 2017). For these variables, distributions used in the simulations were fitted using the BestFit function of @Risk and are presented in Supplemental Table S2 (https://doi.org/10.3168/ jds.2020-18588). This function selects the best-fitting distribution based on the lowest value for the Akaike information criterion. Stochasticity for the rest of the inputs (i.e., variables without historical data such as hormone and semen cost, RP feed cost, and other operating expenses) was generated using a pert distribution with the average price calculated for this study as the most likely value and a $15 \%$ reduction or increment as minimum and maximum values, respectively. For instance, the cost of a CIDR device (including labor) was $\$ 12.70 /$ device (most likely), with minimum and maximum values of $\$ 10.80$ and $\$ 14.60$, respectively. Values for the parameters used for each distribution are presented in Supplemental Table S2.

\section{Statistical Analysis}

Binary outcomes [proportion of heifers AIE; pregnancies per AI (P/AI); proportion of heifers that left the herd, calved, had stillbirths, had a calving ease $>2$, and had a female calf] were analyzed using logistic regression with the GLIMMIX procedure of SAS (version 9.4, SAS Institute Inc., Cary, NC) fitting a binomial distribution. Continuous quantitative outcomes [RP and FLP duration, AFC, BW at 1st calving, DMI, milk yield, incomes (milk income, calf value, IOFC), expenses (reproductive cost, replacement cost, feed cost, and other operating expenses), and cash flow] were analyzed by ANOVA using PROC MIXED of SAS. Time 
Table 1$)$, and was similar $(P=0.21)$ for heifers that received AIE after $\mathrm{PGF}_{2 \alpha}$-synchronized estrus $(46.1 \%$; n $=582)$, AIE during the 5 -d Cosynch $(45.7 \% ; \mathrm{n}=127)$, or completion of the TAI protocol $(40.1 \%$; $\mathrm{n}=257)$. Similarly, overall P/AI for all second and greater AI services combined was not different among treatments $(P=0.72$; Table 1$)$.

The hazard of pregnancy for up to $100 \mathrm{~d}$ after the beginning of the AIP was greater for the ALL-TAI than the PGF+AIE treatment (Table 1) but was similar for the PGF+AIE and PGF+TAI treatments, and for the ALL-TAI and PGF+TAI treatments. Conversely, the proportion of heifers not pregnant by $100 \mathrm{~d}$ after the beginning of the AIP was not different $(P=0.97$; Table 1) among treatments.

Overall, the total proportion of heifers that left the herd during the RP did not differ $(P=0.33$; Table 1 ), because treatment did not affect the proportion of heifers sold $(P=0.23)$ or that died $(P=0.23)$ during the RP.

The length of the RP (i.e., time from the beginning of the AIP until calving or herd exit), was greatest for the PGF+AIE, intermediate for the PGF+TAI, and least for the ALL-TAI treatment, when only heifers that completed the 15-mo experimental period $(P=$ 0.01 ) were included in the analysis (Table 1$)$. In contrast, when analyzed per slot (i.e., including replacement dynamics) RP length was not different $(P=0.35$; Table 1) among treatments.

\section{Economic Outcomes for the Rearing Period}

The effect of treatments on economic outcomes during the RP is presented in Table 2. Reproductive cost was greater $(P<0.001)$ for the ALL-TAI than for the PGF+AIE and PGF+TAI treatments. In contrast, no difference was observed for DMI $(P=0.23)$, feed cost $(P=0.23)$, replacement cost $(P=0.14)$, and other operating expenses $(P=0.35)$. When only heifers that completed the 15-mo experimental period were included in the analysis (i.e., not culled only), reproductive cost was also greater $(P<0.001)$ for the ALL-TAI than the PGF+AIE and PGF+TAI treatments. In addition, for these heifers treatment also affected DMI $(P=0.01)$, feed cost $(P=0.01)$ and other operating expenses $(P=0.01)$, as all were greatest for $\mathrm{PGF}+\mathrm{AIE}$, intermediate for PGF+TAI, and lowest for the ALL-TAI treatment.

Table 2. Effect of first-service management strategy on expenses during the rearing period

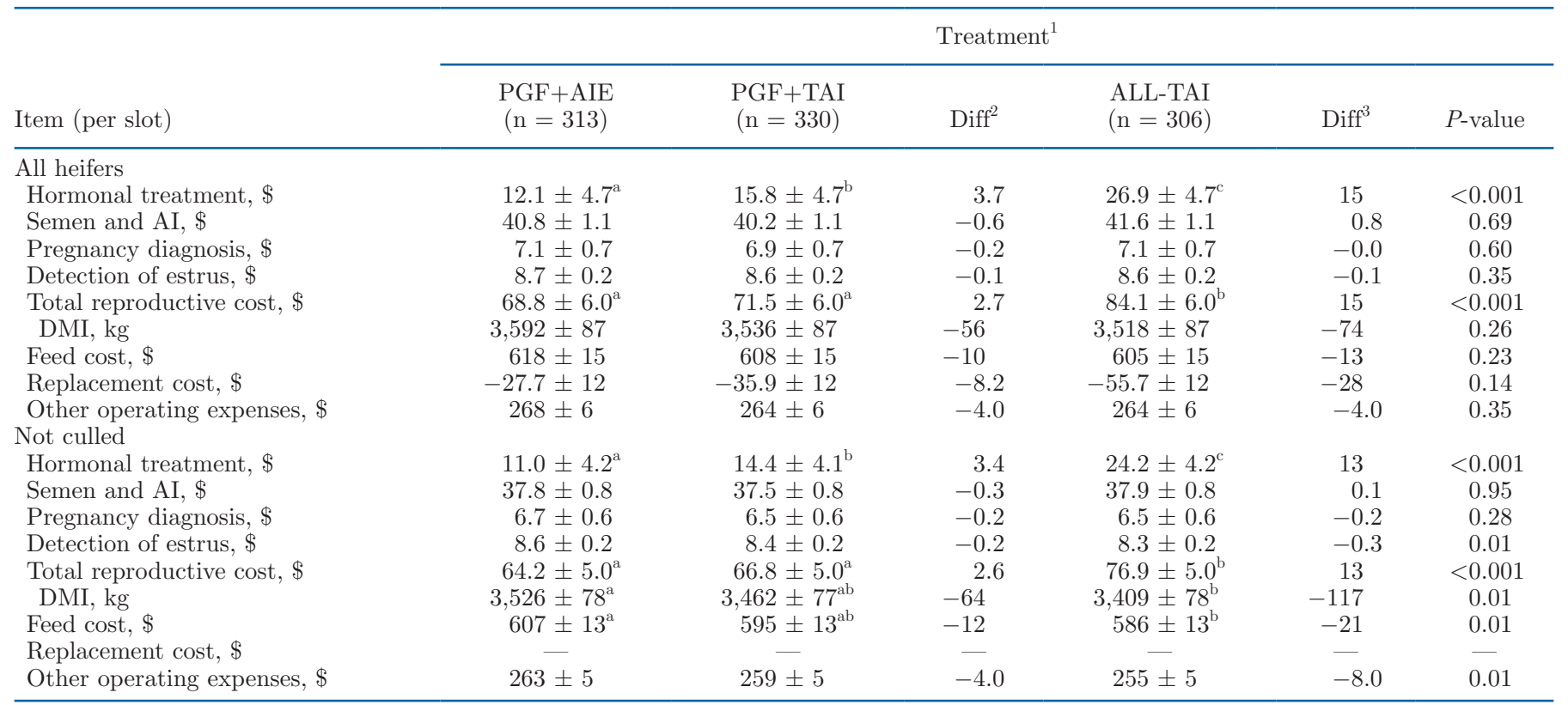

${ }^{\mathrm{a}-\mathrm{c}}$ Different superscripts within a row indicate significant differences $(P \leq 0.05)$.

${ }^{1}$ Treatment: at $368 \pm 10 \mathrm{~d}$ of age, heifers received first AI after: $(1)$ PGF + AIE: insemination at detected estrus (AIE) after PGF ${ }_{2 \alpha}$ treatments $14 \mathrm{~d}$ apart (up to 3) starting at the beginning of the AI period; heifers not AIE within $9 \mathrm{~d}$ of the third PGF $\mathrm{P}_{2 \alpha}$ treatment were enrolled in a $5 \mathrm{~d}$-Cosynch protocol [5d-Cosynch $=$ controlled internal drug release insert $\left.(\mathrm{CIDR})+\mathrm{GnRH}-5 \mathrm{~d}-\mathrm{CIDR}-\mathrm{out}+\mathrm{PGF}_{2 \alpha}-3 \mathrm{~d}-\mathrm{GnRH}+\mathrm{TAI}\right] ;(2)$ PGF+TAI: AIE after the second of $2 \mathrm{PGF}_{2 \alpha}$ treatments $14 \mathrm{~d}$ apart; heifers not AIE within $9 \mathrm{~d}$ after the second PGF ${ }_{2 \alpha}$ were enrolled in $5 \mathrm{~d}-$ Cosynch; and (3) ALL-TAI: timed AI after a 5d-Cosynch protocol.

${ }^{2}$ Difference between PGF+TAI and PGF+AIE.

${ }^{3}$ Difference between ALL-TAI and PGF+AIE. 
Table 3. Effect of first-service management strategy on calving features and herd exit dynamics during the first lactation

\begin{tabular}{lcccc}
\hline & \multicolumn{3}{c}{ Treatment $^{1}$} \\
\cline { 2 - 3 } Item & PGF+AIE & PGF+TAI & ALL-TAI & P-value \\
\hline Calved, \% (no.) & $95.0(313)$ & $94.4(330)$ & $92.4(306)$ & 0.34 \\
Age at 1st calving, mo & $22.3 \pm 0.1^{\mathrm{a}}$ & $22.1 \pm 0.1^{\mathrm{ab}}$ & $22.0 \pm 0.1^{\mathrm{b}}$ & 0.01 \\
Weight at 1st calving, kg & $565 \pm 4$ & $559 \pm 5$ & $557 \pm 5$ & 0.42 \\
Calving ease >2 & $4.4(264)$ & $5.8(281)$ & $8.1(250)$ & 0.23 \\
Stillbirths, \% (no.) & $10.6(297)$ & $7.2(310)$ & $11.1(282)$ & 0.21 \\
Female calves, \% (no.) & $68.0(297)$ & $68.4(310)$ & $65.4(280)$ & 0.70 \\
Left the herd, \% (no.) & $8.8(297)$ & $6.6(311)$ & $8.6(282)$ & 0.53 \\
Sold, \% (no.) & $7.2(297)$ & $5.6(311)$ & $7.6(282)$ & 0.60 \\
Died, \% (no.) & $1.7(287)$ & $1.0(311)$ & $1.1(282)$ & 0.70 \\
1st lactation period length, d & & & & \\
Not culled & & & & 0.07 \\
Per slot & $148 \pm 6$ & $152 \pm 6$ & $155 \pm 6$ & 0.35 \\
\hline
\end{tabular}

$\overline{\mathrm{a}, \mathrm{b}}$ Different superscripts within a row indicate significant differences $(P \leq 0.05)$.

${ }^{1}$ Treatment: at $368 \pm 10 \mathrm{~d}$ of age, heifers received first AI after: 1) PGF+AIE: insemination at detected estrus (AIE) after $\mathrm{PGF}_{2 \alpha}$ treatments $14 \mathrm{~d}$ apart (up to 3 ) starting at the beginning of the AI period; heifers not AIE within $9 \mathrm{~d}$ of the third $\mathrm{PGF}_{2 \alpha}$ treatment were enrolled in a $5 \mathrm{~d}$-Cosynch protocol [5d-Cosynch $=$ controlled internal drug release insert (CIDR) + GnRH-5 d-CIDR-out $+\mathrm{PGF}_{2 \alpha}-3$ d-GnRH + TAI]; 2) PGF+TAI: AIE after the second of $2 \mathrm{PGF}_{2 \alpha}$ treatments $14 \mathrm{~d}$ apart; heifers not AIE within $9 \mathrm{~d}$ after the second $\mathrm{PGF}_{2 \alpha}$ were enrolled in 5d-Cosynch; and 3) ALL-TAI: timed AI after a 5d-Cosynch protocol.

${ }^{2}$ Heifers that were sold or died during the rearing period and first lactation period were removed from the analysis.

\section{Calving Features and Herd Exit Dynamics}

Overall, the proportion of heifers that calved within 15-mo after the beginning of the AIP was similar $(P=0.34$; Table 3$)$. In contrast, AFC differed $(P=$ 0.01 ) among treatments because it was greater for the PGF+AIE than for the ALL-TAI treatment, but similar for the $\mathrm{PGF}+\mathrm{AIE}$ and $\mathrm{PGF}+\mathrm{TAI}$ treatments (Table 3).

For heifers with data for BW at first calving available $(\mathrm{n}=489)$, BW averaged $560 \mathrm{~kg}$ and did not differ $(P=$ 0.42 ) between treatments (Table 3). Similarly, among heifers with calving ease data available $(\mathrm{n}=797)$, the proportion with a calving ease score $>2$ did not differ $(P=0.23)$ between treatments (Table 3$)$. In addition, no difference between treatments was observed for the proportion of stillbirths $(P=0.21)$, proportion of female calves born $(P=0.70)$, and for the proportion of heifers that left the herd due to sale or death $(P=$ $0.53)$.

When only heifers that completed the 15 -mo period were included in the analysis, overall FLP length tended $(P=0.07)$ to differ between treatments. Conversely, when analyzed per slot FLP length did not differ $(P=$ 0.35 ) between treatments (Table 3 ).

\section{First Lactation Period Economic Outcomes}

The effect of treatments on economic and productive outcomes during the FLP is presented in Table
4. When all heifers were included in the analysis, no differences $(P>0.10)$ were observed for DMI, feed cost, milk yield, milk income, IOFC, replacement cost, and other operating expenses. Conversely, we observed a tendency $(P=0.08)$ for a treatment effect on calf value, whereby cows in PGF+TAI treatment had the greatest calf value, followed by the PGF+AIE treatment and least for the ALL-TAI treatment (Table 4). When only heifers that completed the 15-mo experimental period were included in the analysis, no differences $(P$ $>0.10$ ) were observed for DMI, feed cost, milk yield, milk income, IOFC, and replacement cost. In contrast, other operating expenses tended $(P=0.07)$ to differ between treatments, whereby expenses were greatest in ALL-TAI, intermediate in PGF+TAI and lowest in PGF+AIE (Table 4). Similarly, there was a tendency $(P=0.08)$ for a treatment effect on calf value, whereby ALL-TAI heifers had the lowest calf value, followed by the PGF+AIE and greatest for PGF+TAI heifers.

\section{Economic Outcomes for 15 mo After the Beginning of the AIP}

The effect of treatments on total RP cost, FLP profit, and the accumulated cash flow for the 15 -mo period is presented in Table 5. When all heifers were included in the analysis, we observed a tendency $(P=0.08)$ for a treatment effect on total RP cost, which was lowest for ALL-TAI, intermediate for PGF+TAI, and highest for the PGF+AIE treatment. In contrast, no treatment 
Table 4. Effect of first-service management strategy on productive parameters, revenues and expenses during the first lactation

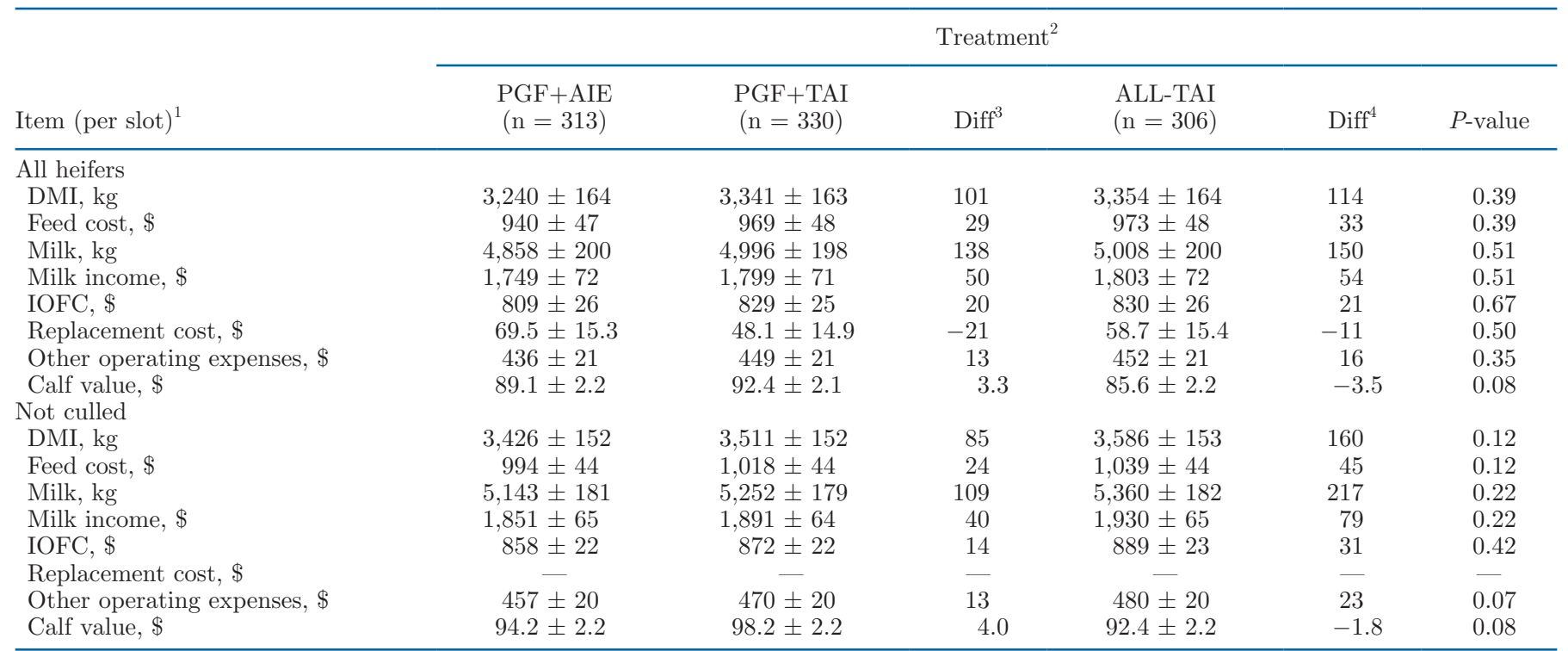

${ }^{1} \mathrm{IOFC}=$ income over feed cost; not culled $=$ heifers that were sold or died during the rearing and first lactation period were removed from the analysis.

${ }^{2}$ Treatment: at $368 \pm 10 \mathrm{~d}$ of age, heifers received first $\mathrm{AI}$ after: (1) PGF+AIE: insemination at detected estrus (AIE) after PGF ${ }_{2 \alpha}$ treatments $14 \mathrm{~d}$ apart (up to 3 ) starting at the beginning of the AI period; heifers not AIE within $9 \mathrm{~d}$ of the third PGF F $_{2 \alpha}$ treatment were enrolled in a 5d-Cosynch protocol [5d-Cosynch $=$ controlled internal drug release insert $\left.(\mathrm{CIDR})+\mathrm{GnRH}-5 \mathrm{~d}-\mathrm{CIDR}-\mathrm{out}+\mathrm{PGF} 2 \mathrm{~g}^{-3} \mathrm{~d}-\mathrm{GnRH}+\mathrm{TAI}\right] ;(2)$ PGF+TAI: AIE after the second of $2 \mathrm{PGF}_{2 \alpha}$ treatments $14 \mathrm{~d}$ apart; heifers not AIE within $9 \mathrm{~d}$ after the second PGF $\mathrm{P}_{2 \alpha}$ were enrolled in $5 \mathrm{~d}-$ Cosynch; and (3) ALL-TAI: timed AI after a 5d-Cosynch protocol.

${ }^{3}$ Difference between PGF+TAI and PGF+AIE.

${ }^{4}$ Difference between ALL-TAI and PGF+AIE.

effect was observed on total FLP profit $(P=0.92)$ and on cash flow for the 15 -mo period $(P=0.22)$. When only heifers that completed the 15-mo experimental pe- riod were included in the analysis, no differences $(P>$ $0.10)$ were observed for total RP cost, total FLP profit, and cash flow for the 15-mo period (Table 5).

Table 5. Effect of first-service management strategy on revenues and expenses accumulated during 15 mo after the beginning of the AI period (AIP)

\begin{tabular}{|c|c|c|c|c|c|c|}
\hline \multirow[b]{2}{*}{$\operatorname{Item}(\$ / \text { slot })^{1}$} & \multicolumn{6}{|c|}{ Treatment $^{2}$} \\
\hline & $\begin{array}{c}\mathrm{PGF}+\mathrm{AIE} \\
(\mathrm{n}=313)\end{array}$ & $\begin{array}{c}\text { PGF+TAI } \\
(\mathrm{n}=330)\end{array}$ & Diff $^{3}$ & $\begin{array}{l}\text { ALL-TAI } \\
(\mathrm{n}=306)\end{array}$ & $\operatorname{Diff}^{4}$ & $P$-value \\
\hline \multicolumn{7}{|l|}{ All heifers } \\
\hline Total RP cost & $928 \pm 18$ & $909 \pm 18$ & -19 & $898 \pm 18$ & -30 & 0.08 \\
\hline Total FLP profit & $393 \pm 20$ & $424 \pm 19$ & 31 & $405 \pm 20$ & 12 & 0.48 \\
\hline Cash flow $15-\mathrm{mo}$ & $-534 \pm 33$ & $-483 \pm 32$ & 51 & $-492 \pm 33$ & 42 & 0.22 \\
\hline \multicolumn{7}{|l|}{ Not culled } \\
\hline Total RP cost & $934 \pm 23$ & $921 \pm 23$ & -13 & $918 \pm 23$ & -16 & 0.36 \\
\hline Total FLP profit & $496 \pm 13$ & $501 \pm 12$ & 5.0 & $503 \pm 13$ & 7.0 & 0.92 \\
\hline Cash flow $15-\mathrm{mo}$ & $-436 \pm 26$ & $-421 \pm 26$ & 15 & $-421 \pm 27$ & 15 & 0.80 \\
\hline
\end{tabular}

${ }^{1} \mathrm{RP}=$ rearing period; FLP $=$ first lactation period; not culled $=$ heifers that were sold or died during the rearing and first lactation period were removed from the analysis.

${ }^{2}$ Treatment: at $368 \pm 10 \mathrm{~d}$ of age, heifers received first AI after: (1) PGF+AIE: insemination at detected estrus (AIE) after $\mathrm{PGF}_{2 \alpha}$ treatments $14 \mathrm{~d}$ apart (up to 3 ) starting at the beginning of the AIP; heifers not AIE within $9 \mathrm{~d}$ of the third $\mathrm{PGF}_{2 \alpha}$ treatment were enrolled in a 5d-Cosynch protocol [5d-Cosynch $=$ controlled internal drug release insert (CIDR) + GnRH-5 d-CIDR-out $+\mathrm{PGF}_{2 \alpha}-3$ d-GnRH + TAI]; (2) PGF+TAI: AIE after the second of $2 \mathrm{PGF}_{2 \alpha}$ treatments $14 \mathrm{~d}$ apart; heifers not $\mathrm{AIE}$ within $9 \mathrm{~d}$ after the second $\mathrm{PGF}_{2 \alpha}$ were enrolled in 5d-Cosynch; and (3) ALL-TAI: timed AI after a 5d-Cosynch protocol.

${ }^{3}$ Difference between PGF+TAI and PGF+AIE.

${ }^{4}$ Difference between ALL-TAI and PGF+AIE. 


\section{Stochastic Analysis}

Differences in cash flow for the 15-mo period after the beginning of the AIP for all heifers included in the study under diverse pricing scenarios are presented in Figure 1. Differences in cash flow between the PGF+TAI and PGF+AIE treatments were $100 \%$ of the time positive values (i.e., in favor of the PGF+TAI treatment). The mean difference after 10,000 iterations was $\$ 53.90$ /slot per 15 mo (95\% CI: $\$ 29.10-84.10)$, and it ranged from $\$ 10.10$ to $\$ 128$. Milk price was the main contributor to the total variance, explaining $\sim 51 \%$ of the total variation in cash flow differences. Greater milk price favored the PGF+TAI treatment. Similarly, differences in cash flow between the ALL-TAI and PGF+AIE ranged from a minimum of $\$ 23.40 /$ slot to a maximum of $\$ 128 /$ slot per $15 \mathrm{mo}$, with a positive average (i.e., in favor of the ALL-TAI treatment) of $\$ 48.80 /$ slot (95\% CI: $\$ 17.20$ to $\$ 84.10)$ with milk price as the main contributor of the total variance $(\sim 40 \%)$. Greater milk price favored the ALL-TAI treatment. Finally, results for the differences in cash flow between the ALL-TAI and PGF+TAI treatments had a mean of $\$-5.01 /$ slot per 15 mo $(95 \%$ CI: $\$-23.40$ to $\$ 12.70)$ and a minimum and a maximum of $\$-51.00$ and $\$ 31.40$, respectively. In this case, the contribution to variance was led by the cost of a new replacement heifer (29\%) closely followed by the cost of a new replacement cow (24\%), and both combined represented $\sim 55 \%$ of the total variation in cash flow differences.

\section{DISCUSSION}

Our study examined economic outcomes for replacement Holstein heifers managed with 3 reproductive management programs that varied in method of submission to first service from almost exclusive use of AIE to exclusive use of TAI. We aimed to provide an all-encompassing comparison that reflected to the best extent possible the conditions of commercial dairy farms. Thus, the main outcome of interest was cash flow per slot for a fixed period of time (i.e., 15 mo after the beginning of the AIP) accounting for the multiple interactions among reproductive performance, productivity, and replacement dynamics as previously reported for lactating dairy cows by our group (Stangaferro et al., 2018, 2019) and others (De Vries, 2004, 2006; Gobikrushanth et al., 2014). The evaluation of cash flow without the effect of the replacement dynamics was explored to isolate the effect of timing of pregnancy because replacement cost can have profound effects on overall cash flow.

The greatest effect of the treatments evaluated on reproductive performance was shifting timing of pregnancy through different insemination risks as the overall first service fertility was similar regardless of the method of submission to AI. Time to pregnancy was reduced for the programs that relied more on TAI with greatest hazard of pregnancy for ALL-TAI, intermediate for PGF+TAI, and lowest for the PGF+AIE program. In spite of these differences, the proportion of heifers pregnant at the end of the observation period and calving was not affected.

A direct consequence of earlier pregnancy for the programs that relied more on TAI was a modest difference in RP length, and consequently AFC, which reduced $\mathrm{RP}$ cost and numerically increased cash flow during the FLP. Collectively, these effects resulted in numerical differences in overall cash flow per slot for the 15-mo period that would be of potential value to commercial dairy farms. Nevertheless, from a strict statistical perspective, our hypothesis of improved cash flow for the programs that incorporated more aggressive use of TAI was not supported. Minor monetary differences and compensation among multiple parameters coupled with large variation among heifers likely explained our observations. The dramatic reduction in cash flow differences among treatments for the analysis including only heifers not culled revealed a smaller contribution of differences in time to pregnancy. Moreover, the different magnitude of change in the differences between treatments illustrated the complexity of the effect of replacement cost on cash flow of dairy animals, especially when accounting for the replacement dynamics during rearing and first lactation. Such prominent role of replacement cost on cash flow highlights the need to account for culling practices and potential cost at the time of selecting or comparing reproductive management programs for replacements. In summary, in spite of the lack of statistical significance and based on the accumulated trends for the rearing and lactation periods accounting or not for heifers that exited the herd, total cash flow trended (in order of magnitude) in favor of the PGF+TAI and ALL-TAI relative to the PGF+AIE program. Thus, under similar conditions than those of our study and assuming that results are repeatable, both programs incorporating systematic use of TAI early after the beginning of the AIP would be expected to improve cash flow of the heifer enterprise as compared with programs similar to PGF+AIE which relied primarily on AIE for submission to the first service.

In support of our other hypothesis, reproductive cost was greater for the ALL-TAI than for the PGF+AIE and PGF+TAI programs. This difference was largely explained by greater hormonal treatment cost, which accounted for $\sim 94 \%$ of the difference in total reproductive cost relative to the PGF+AIE program. These 
A

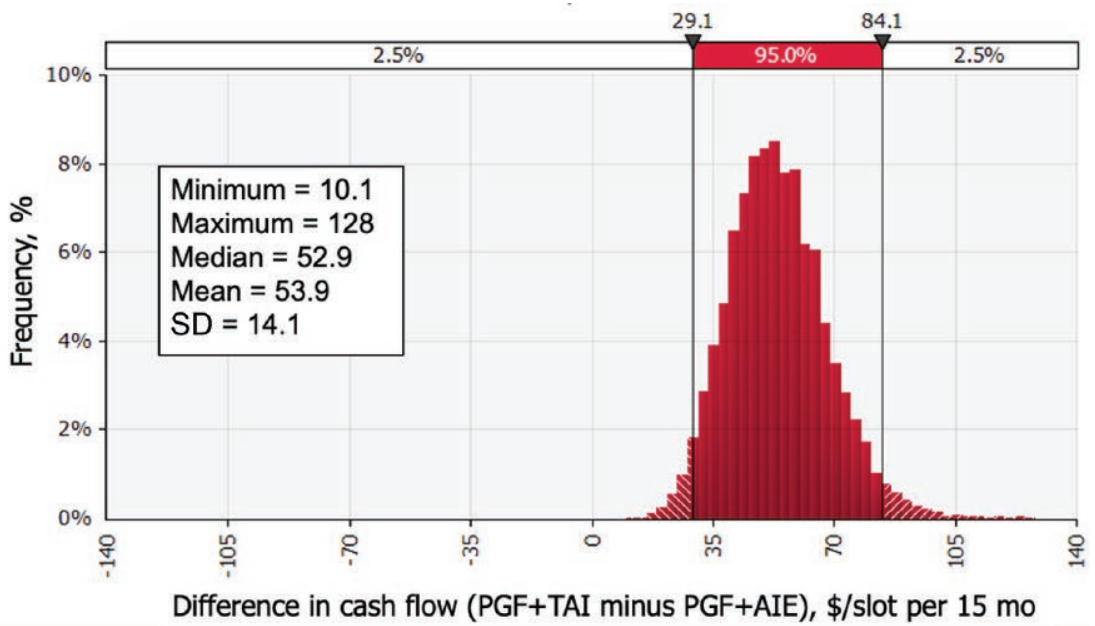

B

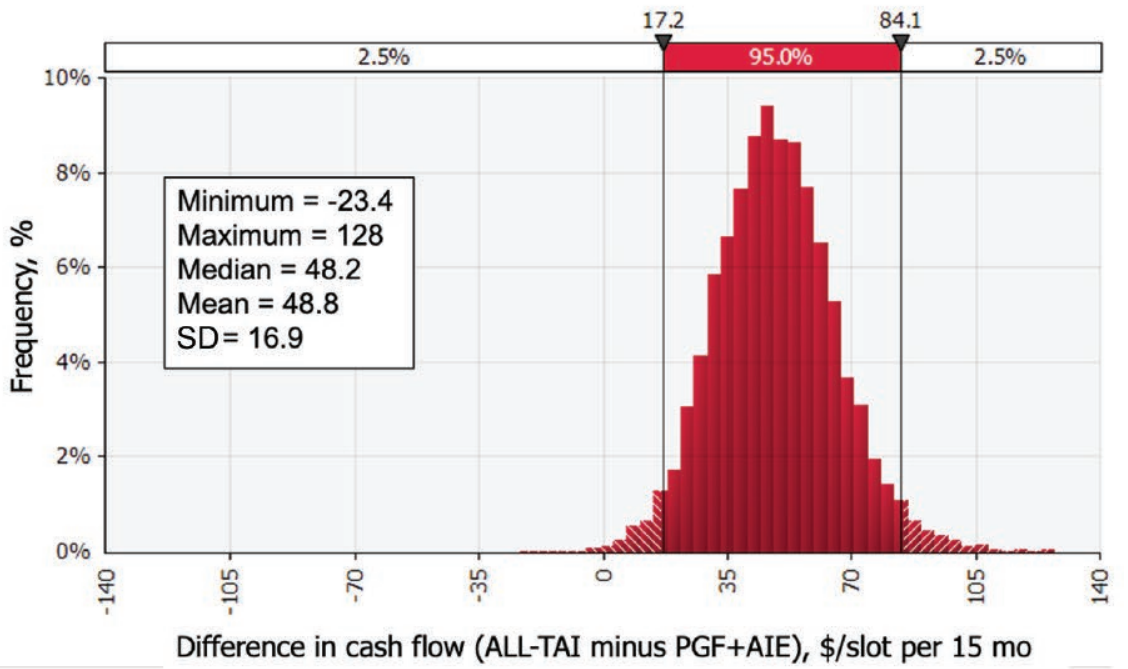

C

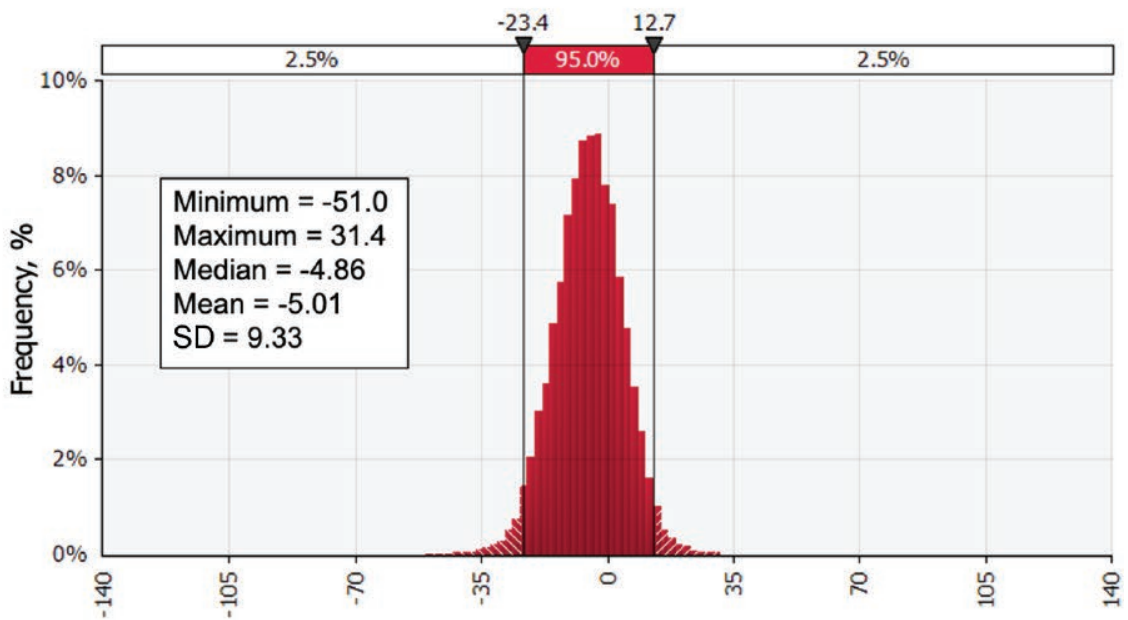

Difference in cash flow (ALL-TAI minus PGF+TAI), \$/slot per 15 mo

Figure 1. Relative frequency distribution of the difference in cash flow (\$/slot per 15 mo) between (A) PGF+TAI and PGF+AIE, (B) ALLTAI and PGF+AIE, and (C) ALL-TAI and PGF+TAI after 10,000 iterations of simulation with stochasticity for economic input values. At 368 $\pm 10 \mathrm{~d}$ of age, heifers received first AI after (1) PGF+AIE: insemination at detected estrus (AIE) after PGF 2 $_{2 \alpha}$ treatments $14 \mathrm{~d}$ apart (up to 3 ) starting at the beginning of the AI period; heifers not AIE within $9 \mathrm{~d}$ of the third $\mathrm{PGF}_{2 \alpha}$ treatment were enrolled in a 5d-Cosynch protocol [5d-Cosynch $=$ controlled internal drug release insert (CIDR) + GnRH-5 d-CIDR-out + PGF2 $\alpha-3$ d-GnRH + TAI]; (2) PGF+TAI: AIE after the second of $2 \mathrm{PGF}_{2 \alpha}$ treatments $14 \mathrm{~d}$ apart; heifers not AIE within $9 \mathrm{~d}$ after the second $\mathrm{PGF}_{2 \alpha}$ were enrolled in 5d-Cosynch; and (3) ALL-TAI: timed AI after a 5d-Cosynch protocol. 
results were expected because previous studies evaluating reproductive management for heifers consistently reported increased hormonal treatment cost for ALLTAI relative to AIE-based programs (Stevenson et al., 2008; Lopes et al., 2013; Silva et al., 2015). On the other hand, the cost of semen and pregnancy diagnosis had a negligible effect on overall reproductive cost $(<\$ 1 /$ slot). Such small effect was likely explained by the overall similar fertility observed across treatments not only for first AI service (sexed semen) but also for second and subsequent AI services (conventional semen). Interestingly, although more heifers received TAI in the PGF+TAI than in the PGF+AIE program, the additional cost of synchronization of ovulation did not translate into greater overall reproductive cost. This was because the minor increment in hormone cost was compensated by the accumulation of minor savings in the other items (i.e., semen and AI, pregnancy diagnosis) that also contributed to reproductive cost.

Despite greater reproductive cost, total cost accrued during the RP tended to be lower for ALL-TAI relative to the PGF+AIE program. Rearing cost for PGF+TAI was intermediate but resembled more closely that of the ALL-TAI treatment. These results were expected, because reduced time to pregnancy for ALL-TAI heifers resulted in lower AFC and consequently a numerical reduction in expenses directly affected by RP duration (i.e., feed cost and other operating expenses). This reduction, however, accounted only for $\sim 28 \%$ of the total difference in total rearing cost. The main contribution to rearing cost differences was for replacement cost ( $\sim 46 \%$ of the difference) which favored the ALLTAI program (statistical tendency). Paradoxically, this was the result of a positive cash flow for heifers that were sold because a heifer sold after the beginning of the AIP was heavier than the heifer that replaced it. Conversely, when removing the effect of replacement dynamics (i.e., culled heifers not included in the analysis) the reduction in RP expense was mostly because of reduced feed cost of ALL-TAI heifers, which accounted for $\sim 50 \%$ of the difference with PGF+AIE heifers. A substantial proportion of this gain, however, was offset by greater hormonal treatment cost, to the extent that no significant differences in total RP cost were observed. In summary, most economic items trended in favor of the PGF+TAI and ALL-TAI relative to the PGF+AIE program. Nonetheless, the differences in timing of pregnancy between treatments were of insufficient magnitude to have a large effect on RP expenses when other expenses not directly associated with RP duration (i.e., replacement and reproductive cost) were accounted for. Of note, reproductive cost was offset regardless of the method to estimate cash flow indicating that as long as timing of pregnancy is reduced, the additional investment in synchronization of ovulation for TAI seemed justified. On the other hand, given the relevance of replacement cost on cash flow differences, it seems reasonable to suggest considering the potential effect of culling practices and market value of animals (i.e., sold and bought) at the time of evaluating reproductive management strategies for heifers.

Regardless of the type of analysis (i.e., all heifers enrolled vs. not culled only), most economic differences during first lactation presented similar trends as those observed for the RP. Reduced AFC for the ALL-TAI treatment translated into numerically greater IOFC. This gain, however, was offset to the extent of resulting in no statistically significant differences for the FLP by factors not directly affected by lactation length (i.e., calf value and replacement cost) and by the greater cost of maintaining lactating cows than heifers (i.e., other operating expenses). The observed unfavorable differences (statistical tendency) for calf value for the ALL-TAI treatment were in line with the slight numerical reduction in the number of born female calves and with the slight increment in the number of stillbirths as compared with the PGF+AIE treatment. Nevertheless, the contribution of calf value to overall FLP profit was inconsequential (i.e., $\$ 3 /$ slot). Similar to the RP, outcomes for the FLP for the PGF+TAI program were mostly intermediate. The tendency for greater calf value and the numerically lower replacement cost resulted in numerically greater FLP profit relative to ALL-TAI. Collectively, we observed that cash flow during the FLP followed expected trends (i.e., greater for ALL-TAI and PGF+TAI than for PGF+AIE), but minor monetary differences and compensation among items not directly affected by the timing of first calving likely resulted in lack of significant differences on total FLP cash flow.

Taken together, data from the RP and FLP suggested that the magnitude of the differences observed in timing of pregnancy and consequently on AFC were of sufficient magnitude to generate numerical differences for cash flow over the 15-mo period that would be of economic value to commercial dairy farms but were of insufficient magnitude to be statistically significant. The latter can be explained by the magnitude of the difference in reproductive performance and the effect of large heifer-to-heifer variation on overall cash flow differences. The small magnitude of the differences in time to pregnancy between treatments was the result of the high insemination risk for the PGF+AIE treatment because a high proportion of heifers received AIE within a short time after the beginning of the AIP (i.e., $78 \%$ AIE after the first $\mathrm{PGF}_{2 \alpha}$ treatment in $\mathrm{PGF}+\mathrm{AIE}$ ) and had similar $\mathrm{P} / \mathrm{AI}$ than heifers in the other treatments. Our results are in agreement with those of $\mathrm{Ri}-$ beiro et al. (2012) who in a simulation study reported 
that the economic benefits of incorporating programs that relied mostly on TAI for managing reproduction of replacement heifers were inconsequential when estrus detection efficiency was at least $70 \%$. In contrast, Silva et al. (2015) reported reduced rearing cost for heifers managed with an ALL-TAI (5-d Cosynch with initial GnRH and $2 \mathrm{PGF}_{2 \alpha}$ treatments) program compared with a predominant AIE-based program, even when a high proportion of heifers were AIE (>80\%) relatively early after the beginning of the AIP. Differences in insemination risk between experiments, and consequently timing of pregnancy imposed by different experimental designs likely explain the contrasts in results observed for our experiment and that of Silva et al. (2015). On the other hand, in spite of the reasonable number of heifers included in each treatment in our study, substantial heifer-to-heifer variation contributed to the lack of statistically significant differences in cash flow per 15 mo. This was a reflection of the major variation in cash flow per slot (range $\$-2,776$ to $\$ 470$; data not shown) driven primarily by large differences in replacement cost and milk income between slots. This is in agreement with recent studies that included a similar comprehensive approach to calculate cash flow of dairy cows managed with different reproductive management programs (Stangaferro et al., 2018, 2019).

Stochastic analysis with Monte Carlo simulation is a useful tool to estimate trends and the expected magnitude of differences in cash flow for different management strategies when multiple inputs and their variation across time might affect cash flow (McArt et al., 2014; McArt and Oetzel, 2015). In this case, we estimated a range of differences in cash flow for the programs compared under a wide range of market conditions. We observed that the PGF+TAI and ALL-TAI treatments were economically favorable relative to the $\mathrm{PGF}+\mathrm{AIE}$ program under all for PGF+TAI or almost all scenarios for ALL-TAI (i.e., > 98\%) suggesting that under a wide range of conditions caused by market fluctuations the programs incorporating more aggressive use of TAI would be beneficial to the economics of the heifer enterprise. Based on the range of values and shape of the distribution for cash flow differences, it was apparent that the PGF+TAI treatment would lead to greater and more consistent positive differences compared with the $\mathrm{PGF}+\mathrm{AIE}$ treatment than the ALL-TAI treatment. Conversely, implementing either the PGF+TAI or ALL-TAI treatments would likely be neutral because values for their cash flow differences were almost equally distributed around zero. Collectively, the results of the stochastic and deterministic analysis suggested that the selection of reproductive management programs for replacement heifers should be made in light of the known or expected insemina- tion risk for AIE or TAI-based programs, the effect of culling practices, and current and future prices for milk and replacements. In addition, the cost of hormonal treatments seemed less relevant because its effect on overall cash flow differences was small compared with the value of earlier pregnancy.

A caveat of our study was that the cash flow estimation did not include the opportunity cost of the investment on the different reproductive programs compared. Nevertheless, estimations of the net present value using a discount rate of $5 \%$ (data not shown) resulted in no difference in the direction and magnitude of the differences between treatments.

\section{CONCLUSIONS}

We concluded that reproductive management programs that used TAI in combination with AIE or TAI as the primary method to submit heifers for first service generated differences in cash flow of potential value to commercial dairy farms. Reduced rearing cost and more revenue generated during the first lactation increased cash flow for up to 15 mo after heifers became eligible for pregnancy under fixed or simulated variable market conditions. Greater reproductive cost due to use of TAI were offset by the positive effect of earlier pregnancy on cash flow of replacements heifers.

\section{ACKNOWLEDGMENTS}

This research was financially supported through a grant (AOR 15-020) from the New York Farm Viability Institute (Syracuse, NY) to J. O. Giordano. We thank the two commercial dairy farms that participated in this research for their support and the use of their cows and facilities. We also extend our gratitude to Zoetis (Parsippany-Troy Hills, NJ) for providing the hormonal products used to synchronize estrus and ovulation. Finally, we thank Jim Ehrlich from DairySights LLC (Argyle, NY) for his calculations of daily milk production using the MilkBot model. The authors have not stated any conflicts of interest.

\section{REFERENCES}

Cornell Cooperative Extension of Chautauqua County. 2018. Dairy Market Watch. Accessed Aug. 8, 2018. http://chautauqua.cce .cornell.edu/resources/

De Vries, A. 2004. Economics of delayed replacement when cow performance is seasonal. J. Dairy Sci. 87:2947-2958. https://doi.org/ 10.3168/jds.S0022-0302(04)73426-8.

De Vries, A. 2006. Economic value of pregnancy in dairy cattle. J. Dairy Sci. 89:3876-3885. https://doi.org/10.3168/jds.S0022 $-0302(06) 72430-4$.

Ehrlich, J. L. 2013. Quantifying inter-group variability in lactation curve shape and magnitude with the MilkBot ${ }^{\circledR}$ lactation model. PeerJ 1:e54. https://doi.org/10.7717/peerj.54. 
Ettema, J. F., and J. E. P. Santos. 2004. Impact of age at calving on lactation, reproduction, health, and income in first-parity Holsteins on commercial farms. J. Dairy Sci. 87:2730-2742. https:// doi.org/10.3168/jds.S0022-0302(04)73400-1.

Gobikrushanth, M., A. De Vries, J. E. P. Santos, C. A. Risco, and K. N. Galvão. 2014. Effect of delayed breeding during the summer on profitability of dairy cows. J. Dairy Sci. 97:4236-4246. https://doi .org/10.3168/jds.2013-7664.

Gould, B. 2017. Understanding dairy markets. National average dairy feed costs. Accessed Dec. 1, 2019. http://future.aae.wisc.edu/ data/monthly_values/by_area/3002.

Harsh, S. B., C. A. Wolf, and E. Wittenberg. 2001. Profitability and production efficiency of the crop and livestock enterprises of Michigan dairy operations: 1998 summary and analysis. Department of Agriculture Economics Staff Paper No. 01-04. Michigan State University, East Lansing, MI.

Higgs, R. J., L. E. Chase, D. A. Ross, and M. E. Van Amburgh. 2015. Updating the Cornell Net Carbohydrate and Protein System feed library and analyzing model sensitivity to feed inputs. J. Dairy Sci. 98:6340-6360.

Hyams, D. G. 2011. CurveExpert Professional Documentation. Release 2.6.5. Accessed Aug. 12, 2018. https://docs.curveexpert.net/ curveexpert/pro/pdf/CurveExpertProfessional.pdf.

Kalantari, A. S., H. Mehrabani-Yeganeh, M. Moradi, A. H. Sanders, and A. De Vries. 2010. Determining the optimum replacement policy for Holstein dairy herds in Iran. J. Dairy Sci. 93:2262-2270. https://doi.org/10.3168/jds.2009-2765.

Karszes, J. 2014. Dairy Replacement Programs: Costs \& Analysis 3rd Quarter 2012. Extension Bulletin 2014-02, Department of Animal Science and Charles H. Dyson School of Applied Economics and Management, Cornell University, Ithaca, NY.

Karszes, J., W. A., Knoblauch, C. Dyamond. 2017. Dairy farm management business summary, New York State, 2016. Charles H. Dyson School of Applied Economics and Management, Cornell University, Ithaca, NY.

Karszes, J., A. Christman, A. Howlett, and W. Knoblauch. 2018. Dairy farm management business summary, New York State, 2017. Charles H. Dyson School of Applied Economics and Management, Cornell University, Ithaca, NY.

Lopes, G. Jr., C. Johnson, L. Mendonça, P. Silva, J. Moraes, A. Ahmadzadeh, J. Dalton, and R. Chebel. 2013. Evaluation of reproductive and economic outcomes of dairy heifers inseminated at induced estrus or at fixed time after a 5-day or 7-day progesterone insert-based ovulation synchronization protocol. J. Dairy Sci. 96:1612-1622. https://doi.org/10.3168/jds.2012-5971.

Masello, M., M. M. Perez, G. E. Granados, M. L. Stangaferro, B. Ceglowski, M. J. Thomas, and J. O. Giordano. 2019. Reproductive performance of replacement dairy heifers submitted to first service with programs that favor insemination at detected estrus, timed artificial insemination, or a combination of both. J. Dairy Sci. 102:1671-1681. https://doi.org/10.3168/jds.2018-15200.

McArt, J. A. A., D. V. Nydam, G. R. Oetzel, and C. L. Guard. 2014. An economic analysis of hyperketonemia testing and propylene glycol treatment strategies in early lactation dairy cattle. Prev. Vet. Med. 117:170-179. https://doi.org/10.1016/j.prevetmed.2014 .06 .017 .

McArt, J. A. A., and G. R. Oetzel. 2015. A stochastic estimate of the economic impact of oral calcium supplementation in postpartu- rient dairy cows. J. Dairy Sci. 98:7408-7418. https://doi.org/10 .3168/jds.2015-9479.

NRC. 2001. Nutrient Requirements of Dairy Cattle, Seventh Revised Edition. National Academies Press, Washington DC.

Progressive Dairyman. 2019. Market Watch: Cattle. Accessed Aug. 30, 2019. https://www.progressivedairy.com/news/organizations/ market-watch-cattle.

Ribeiro, E. S., K. N. Galvão, W. W. Thatcher, and J. E. P. Santos. 2012. Economic aspects of applying reproductive technologies to dairy herds. Anim. Reprod. 9:370-387.

Silva, T. V., F. S. Lima, W. W. Thatcher, and J. E. P. Santos. 2015. Synchronized ovulation for first insemination improves reproductive performance and reduces cost per pregnancy in dairy heifers. J. Dairy Sci. 98:7810-7822. https://doi.org/10.3168/jds.2015-9704.

Stangaferro, M. L., R. W. Wijma, and J. O. Giordano. 2019. Profitability of dairy cows submitted to the first service with the Presynch-Ovsynch or Double-Ovsynch protocol and different duration of the voluntary waiting period. J. Dairy Sci. 102:4546-4562. https://doi.org/10.3168/jds.2018-15567.

Stangaferro, M. L, R. Wijma, M. Masello, M. J. Thomas, and J. O. Giordano. 2018. Economic performance of lactating dairy cows submitted for first service timed artificial insemination after a voluntary waiting period of 60 or 88 days. J. Dairy Sci. 101:75007516. https://doi.org/10.3168/jds.2018-14484.

Stevenson, J. L., J. A. Rodrigues, F. A. Braga, S. Bitente, J. C. Dalton, J. E. P. Santos, and R. C. Chebel. 2008. Effect of Breeding Protocols and Reproductive Tract Score on Reproductive Performance of Dairy Heifers and Economic Outcome of Breeding Programs1. J. Dairy Sci. 91:3424-3438. https://doi.org/10.3168/jds .2007-0804.

USDA Agricultural Marketing Service. 2019. Milk marketing order statistics. Individual milk order prices. Accessed Dec. 1, 2019 https://www.ams.usda.gov/resources/marketing-order-statistics/ uniform-price

USDA Economic Research Service. 2019. US quarterly milk production and related data. Accessed several times from 2018 to 2019 Accessed Dec. 1, 2019. https://www.ers.usda.gov/data-products/ dairy-data/

USDA National Agricultural Statistics Service. 2019. Agricultural Prices. Accessed several times from 2018 to 2019. Accessed Dec. 1, 2019. https://www.nass.usda.gov/

van Arendonk, J. A. M. 1985. A model to estimate the performance, revenues and costs of dairy cows under different production and price situations. Agric. Syst. 16:157-189. https://doi.org/10.1016/ 0308-521X(85)90010-1.

Winsor, C. P. 1932. The Gompertz curve as a growth curve. Proc. Natl. Acad. Sci. USA 18:1-8. https://doi.org/10.1073/pnas.18.1.1.

\section{ORCIDS}

M. Masello ๑ https://orcid.org/0000-0001-9573-1786 M. M. Perez $\odot$ https://orcid.org/0000-0002-9626-8735 G. E. Granados @ https://orcid.org/0000-0002-2457-1997 M. L. Stangaferro ํ https://orcid.org/0000-0001-6408-669X M. J. Thomas (® https://orcid.org/0000-0002-6837-7352

J. O. Giordano @ https://orcid.org/0000-0003-1455-6811 